\title{
Thermal Spraying Processes and Amorphous Alloys: Macro-Indicators of Patent Activity
}

\author{
Bráulio Salumão de Oliveira $^{a *}$, Douglas Henrique Milane $z^{a, b}$, Daniel Rodrigo Leiva ${ }^{a}$, Leandro \\ Innocentini Lopes de Faria ${ }^{a}$, Walter José Botta ${ }^{b}$, Claudio Shyinti Kiminami ${ }^{b}$
}

\begin{abstract}
${ }^{a}$ Núcleo de Informação Tecnológica em Materiais, Departamento de Engenharia de Materiais, Universidade Federal de São Carlos, Rod. Washington Luis, km 235, São Carlos, SP, Brazil ${ }^{b}$ Laboratório de Materiais Amorfos e Nanoestruturados, Departamento de Engenharia de Materiais, Universidade Federal de São Carlos, Rod. Washington Luis, km 235, São Carlos, SP, Brazil
\end{abstract}

Received: April 28, 2017; Revised: September 29, 2017; Accepted: October 27, 2017

\begin{abstract}
Thermal spraying processes allows high cooling rates and can favor the formation of amorphous microstructures. Amorphous metallic coatings can result in superior mechanical and functional properties. To follow new technological development and innovation paths, indicators based on patent data can be assembled to support technological forecasting assessments and decision making. This study mapped the technological development on amorphous alloys processed by thermal spraying using patent indicators from documents indexed in the Derwent Innovations Index database between the years 1997 and 2014. We evaluate the patent activity, the role of countries, the main technological subdomains and markets of interest, as well as the main metallic alloys explored as coating. We conclude that new technological developments should be expected in near future and these advances both in amorphous alloys and thermal spraying shall be constantly monitored in the coming years.
\end{abstract}

Keywords: Amorphous alloys, Thermal Spraying, Patent Indicators.

\section{Introduction}

Amorphous and glassy metals can be understood as non-crystalline solids formed by the rapid quenching techniques $\left(10^{2}-10^{6} \mathrm{~K} / \mathrm{s}\right)$ of engineered compositions usually involving three and more metallic elements with large atomic size rations. They attracted much attention recently due to their striking combination of mechanical, physical, and chemical properties. For example, iron-based metallic glasses are known for their good magnetic properties, high hardness, superior corrosion and wear resistance ${ }^{1-3}$. The research effort on developing amorphous metallic alloys has target their potential fields of application in machinery and cutting materials, corrosion resistant material, hydrogen storage materials, metal-matrix composites, sporting goods materials, soft magnetic and high magneto strictive materials ${ }^{2}$. However, the processed glass metal usually presents small thickness or diameter sections, i.e. powders, ribbons and wires, as consequence of the limitations from the processes available currently, even though bulk metallic glass can be obtained for certain alloys 4 .

Thermal spraying techniques have gained much attention to produce coatings of metallic glasses in metallic substrate to improve wear and corrosion resistances ${ }^{5-9}$. The use of glassy metals as coatings enhanced the service life of parts and

*e-mail: brauliosalumao@gmail.com equipments, such as pipes and other steel-made components from oil and gas industry ${ }^{5}$. Thermal spraying deposition of amorphous metallic alloys combines a spray of molten or semi-molten particles accelerated to a substrate to form the coating. It uses electrical and chemical sources to heat a consumable material and the velocity of air, oxygen, argon, or other gases to project the particle to the substrate ${ }^{4,10,11}$. There are many techniques that can be used to form the final coating, such as plasma spraying, wire arc spraying, flame spraying, high velocity oxygen fuel, and high velocity air fuel ${ }^{6,11-13}$. In this context, warm-spraying and cold-spraying processes $^{14,15}$ can be included, although in these cases lower temperatures are involved, and enhancing the velocity of the particles is the key to form the amorphous phase.

Emerging of new materials and processes can be followed by technological forecasting and monitoring methods, which aims to provide strategic information and to support decision making, funding, research and development (R\&D), and public policies ${ }^{16-19}$. Technological monitoring answers "who is doing what" and there are many technological forecasting methods involving both qualitative and quantitative analysis. However, quantitative techniques have been preferred used as consequence of the huge volume of data and information available nowadays.

Among the sources of technological information, patent documents highlights because they contain valuable 
information, such as date of first filing, as well as country where it was firstly applied, assignee names, and the International Patent Classification (IPC), which is a codified classification system that provide the general aspects of the invention described in the document ${ }^{20,21}$. Bibliometrics can be used to assess quantitatively patent documents, because it can deal properly with the current volume of information available; it can also provide trend analyses of patterns not easily perceptible. Furthermore, there are worldwide covered patent databases that allows a comparative analysis of countries and organizations behaviors and interests ${ }^{20-27}$.

In this study, we monitor the advances on metallic glass coatings applied by thermal spraying processes using patent indicators. We focused on the temporal evolution assessment, geographical position of patent holders, as well the sectors of technological interest. In addition, the most used metallic alloys by companies, universities and research centers were depicted.

\section{Data and Method}

\subsection{Collecting patents data}

We used keywords regarding thermal spraying process and amorphous alloys collected from scientific papers and patent documents to compose the final search expressions. We also added codes from the International Patents
Classification $^{28}$ (IPC) that describe the object of the research, i.e. amorphous/glassy metals (C22C-045 subgroups ${ }^{\mathrm{a}}$ ) and thermal spraying process (C22C-047/16, C22C-047/18 ${ }^{\mathrm{b}}$ and C23C-004 subgroups ${ }^{\mathrm{c}}$ ). The searches were conducted at the worldwide Derwent Innovations Index database, which comprises patents structured records with a worldwide coverage $^{29}$. The search expressions were performed with the purpose of retrieving information contained in the titles, abstracts and IPC codes of the bibliographic data of patent documents, as presented at Table 1 . The table also provides total number of patent documents found from each step. All searches were conducted in 12 December 2016.

From search \#1 up to \#12, the main objective was to find the documents related to thermal spray processes. The search expression \# 13, presents the intersection of this result with a previous elaborated search strategy with keywords and IPCs codes related to amorphous/glassy alloys. The final sample comprised 213 bibliographic data of patent document families ${ }^{\mathrm{d}}$ filed until 2014. We did not account patents filed between 2015 and 2016 because in the patent system, the documents are not published before one or two years after application.

\subsection{Data analysis techniques}

The indicators were prepared according the recommendations of OCDE Manuals ${ }^{20,21}$. In order to recover the priority dates of the documents, all data from the final search were recovered

Table 1. Search expressions used in the Derwent Innovations Index for retrieving records of patent documents regarding amorphous alloys and thermal spraying processes.

\begin{tabular}{clc}
\hline$\#$ & Search Expression & Results \\
\hline $\mathbf{1}$ & TS="thermal spray*" & 6.040 \\
$\mathbf{2}$ & TS="wire arc spray*" & 87 \\
$\mathbf{3}$ & TS="plasma spray*" & 4.925 \\
$\mathbf{4}$ & TS="flame spray*" & 3.632 \\
$\mathbf{5}$ & TS=("high velocity oxy-fuel*" OR "high velocity oxygen fuel*" OR HVOF) & 502 \\
$\mathbf{6}$ & TS=("low velocity oxy-fuel*" OR "low velocity oxygen fuel*" OR LVOF) & 5 \\
$\mathbf{7}$ & TS=("high velocity air-fuel*" OR HVAF) & 48 \\
$\mathbf{8}$ & TS=("warm spray*") & 16 \\
$\mathbf{9}$ & TS=("cold spray*") & 891 \\
$\mathbf{1 0}$ & IP=(C22C-047/16 OR C22C-047/18) & 50 \\
$\mathbf{1 1}$ & IP=(C23C-004*) & 15.209 \\
$\mathbf{1 2}$ & \#11 OR \#10 OR \#9 OR \#8 OR \#7 OR \#6 OR \#5 OR \#4 OR \#3 OR \#2 OR \#1 & 24.136 \\
$\mathbf{1 3}$ & \#12 AND TS=("amorphous metal*" OR "amorphous alloy*" OR " metal* glass*" OR & 223
\end{tabular}

TS: Topic (title and abstract); IP: International Patent Classification code; AND, OR: Boolean operators.

\footnotetext{
a The code $\mathrm{C} 22 \mathrm{C}-045$ belongs to the subclass of metallic alloys (C22C) and it refers specifically to amorphous alloys.

${ }^{\mathrm{b}}$ Both codes C22C-047/16 and C22C-047/18 belong to the subgroup detail of making alloys containing metallic or non-metallic fibers or filaments by thermal spraying of the metal, using or not a preformed structure of fibers or filaments.

${ }^{c}$ The code $\mathrm{C} 23 \mathrm{C}-004$ belongs to the broad subclass of coating metallic material (C23C) and it refers specifically to coating by spraying the coating material in the molten state using flame, plasma or electric discharge. All IPC code meaning can be consulted in the website: http://web2.wipo.int/classifications/ipc

${ }^{\mathrm{d}}$ A patent family comprises patent applications about the same invention applied in different countries. The analyses based on patent families provides a worldwide analysis without counting duplicates.
} 
and treated by the Earliest Priority Selector ${ }^{30}$ (EPS) software, and then imported to the Vantage Point (5.0 version) in which bibliometric calculations could be performed. All charts and tables were made using Microsoft Excel (2016 version).

The analysis was performed for the documents with priority date between the years of 1997 (beginning of major patent activity at this area) and 2014. For the temporal evolution analysis, the numbers of patent applications were counted in triennials and the main holders were classified by its principal activity as universities or public research centers and companies. In addition, the percentage of documents of search \# 13 inside \# 12 results was considered in order to evaluate the representation of documents related to amorphous alloys within the universe of thermal spraying processes.

For the geographical analysis, the priority countries of the patent were considered, that is, where it was deposited for the first time. It was also evaluated in which countries patent protection was required for each document.

We used the IPC codes to verify the main technological subdomains - which can be associated to the main sector of industry, and also to identify which metallic alloys are being preferred used on developments. In the case of technological subdomains, the IPC codes were clustered considering the recommendations from the Observatoire des Sciences et des Technologies ${ }^{31,32}$ (OST). This classification groups IPC codes related to the same technology sector, even if they belong to different sections of the IPC.

To understand which amorphous/glassy alloy have been target of development from companies and universities or research institutes, we identified all IPC codes (subgroup level) for metallic alloys ${ }^{\mathrm{e}}$, i.e. those classified from the C22C-05 to C22C-45 (alloys). The main codes identified belonged to the IPC code $\mathrm{C} 22 \mathrm{C}-045$ (level) ${ }^{\mathrm{f}}$, which divides in Fe-based amorphous alloys (C22C-045/02), Ni- or Cobased amorphous alloys (C22C-45/04), Al-based amorphous alloys (C22C-45/08) and Mo-, W-, Nb-, Ta-, Ti-, Zr-based amorphous alloys (C22C-45/10). Other IPC codes were also identified (34 in total) and we considered them in the mapping evaluation, because they provide alloy elements from metallic compositions. However, we separated the main classification for amorphous alloys (C22C-45) from them, since they have a low number of patents associated (less than 10) and they are connected to those amorphous/glassy IPC codes. The sample of patent documents that contain at least one IPC code of a metallic alloy was 78 .

By crossing the alloys and type of assignee in terms of patent documents, we obtained a raw network that was analyzed using VOSviewer software ${ }^{33,34}$. We selected the association strength method for normalizing the strength of the links between items (i.e. alloys and type of assignees). Finally, the representativeness (R) was calculated using Eq.1 where $\mathrm{N}_{i}$ is the number of patent documents from a period or technological subdomain (i) and $\mathrm{N}_{t}$ is the total of patent documents in the context of analysis $(t)$.

$$
R(\%)=\frac{N_{i}}{N_{t}} x 100
$$

\section{Results and Discussion}

\subsection{Overall patent activity on thermal spraying process}

The overall patent activity of thermal spraying processes can be tracked from the final of the 1970 years, when it increased rapidly, until the end of 1980-decade due to the interest of industry and scholars to develop the firsts coatings of ceramics, metals and polymers. During the 1990 decade, the number of patent applications on thermal spraying was leveled out with a medium number of 540 documents per year. Plasma spraying and flame spraying were the focus of developments, yet in both mentioned decades, the total number of patent applications involving amorphous/glassy metallic coatings were low (from 1 to 3 ).

The number of patent applications for thermal spraying processes in general experienced a new increase in the end of 1990-decade, however the use of amorphous/glass alloys as coating grew effectively only after 2004 . Figure 1 provides the general trend of thermal spraying processes activity, involving ceramics, metals (crystalline and non-crystalline) and polymers. Figure 1 also contains the percentage number of thermal spraying-related patents that claimed an amorphous/ glassy alloy composition as coatings.

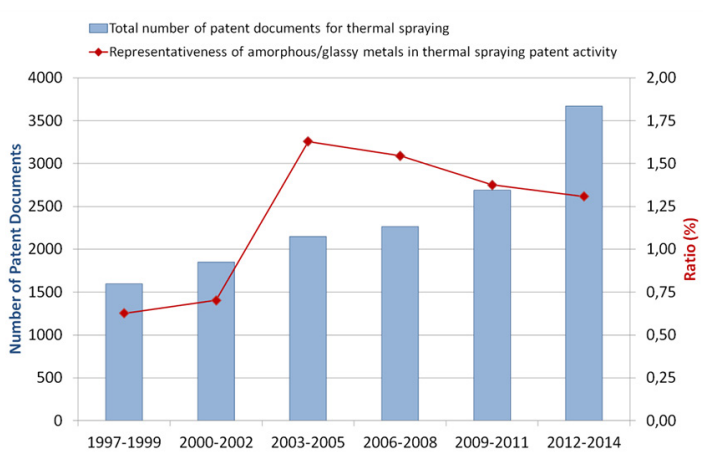

Figure 1. Number of patent documents in thermal spraying processes and relative percentage of amorphous alloys recovered from Derwent Innovations index in the period between 1997 and 2014. Source: Derwent Innovations Index.

The representativeness of amorphous/glassy metals-related patents to thermal spraying processes decrease from $1,63 \%$

${ }^{\mathrm{e}}$ In the IPC, metallic alloys are classified in the subclass $\mathrm{C} 22 \mathrm{C}$, having a specific code from $\mathrm{C} 22 \mathrm{C}-05$ to $\mathrm{C} 22 \mathrm{C}-45$. This subclass also provides processing techniques and forms of the final product, but they were not considered.

${ }^{\mathrm{f}}$ The IPC code C22C-45/06 - Be-based amorphous alloys was not considered in this study since none patent was classified by this code. 
in $2003-2005$ period to $1.31 \%$ in the last period of years considered. Nonetheless, the sudden interest in amorphous/ glassy metals (2003-2005) coincides with the growing number of patents filled by universities and research institutes as well as on Fe-based amorphous alloys.

We can state that the use of amorphous/glassy metallic alloys as coatings is currently at an emerging stage of development, because it still depends on scientific-based research and with few products and processes available. Furthermore, the low percentage observed may also be associated to applicants' strategy of not to clearly indicate whether an amorphous/glassy metal was used by their invention. The result also suggests that new developments on this area are expected, due to the average number of patents applied between 2005 and 2014 (only 13). Furthermore, the technological advances are focused on the process, not in the materials development.

\subsection{Technological indicators on amorphous metallic coatings obtained by thermal spraying process}

Companies have been leading the technological development of coatings made by amorphous/glassy metallic alloys, as can be seen in the Figure 2. The field has also experienced an increase in the number of patents from universities and research institutes since 2004, which support the emerging stage of development hypothesis. Of course, there are many options of thermal spraying processes available, and each one of them can be stated in a different stage of development. Plasma spraying, flame spraying and HVOF can be considered mature techniques and highly used by industries, while warm spraying is still a new option. Nonetheless, we are assessing this whole technical field associated to the use amorphous/ glassy metals, which still depend highly on basic research. That also explains the patents in collaboration of companies with universities or research institutes.

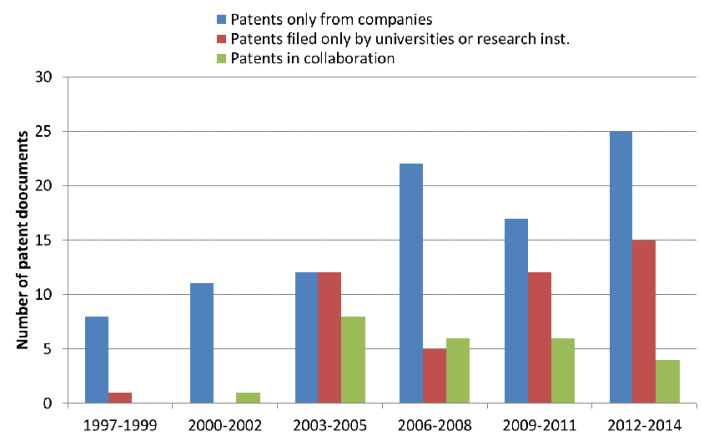

Figure 2. Categories of main patent holders on amorphous alloys processed by thermal spraying processes between the years of 1997 and 2014. Source: Derwent Innovations Index.

Before 1997, Japan filed the highest number of patents on thermal spraying to produce amorphous/glassy metallic coatings, and they still present a trend of increase among the periods. In terms of accumulative number of patents, the USA leads the ranking of countries, yet their annual number of patent applications on amorphous/glassy metallic coatings did not changed lately, as can be seen from Figure 3. Japanese's companies assigned $98.2 \%$ of the Japanese patents while American's companies hold $82.8 \%$ - a fact that should be associated to their mature innovation system. On the other hand, the number of patents from China boomed recently and this behavior is not exclusively of the present topic, yet also observed on other technologies, such as pipeline steels $^{35}$, hydrogen storage materials ${ }^{36}$ and laser coating ${ }^{37}$. It may be related to China's restructuring plan on its science, technology and innovation system, which is strongly based on its research institutes and universities ${ }^{38,39}$ - in this study they account for $74.4 \%$ while Chinese's companies assigned only for $27.9 \%$. Germany, France and Korea accumulated a low number of patent applications in the whole timespan analyzed here, with companies filing more patents than universities and research institutes $-77.8 \%$ in Germany and $90.0 \%$ in France, except in the case of Korea, where the second type of assignee held $71.4 \%$ of all Korean patents - again the difference among these countries innovation system is highlighted.

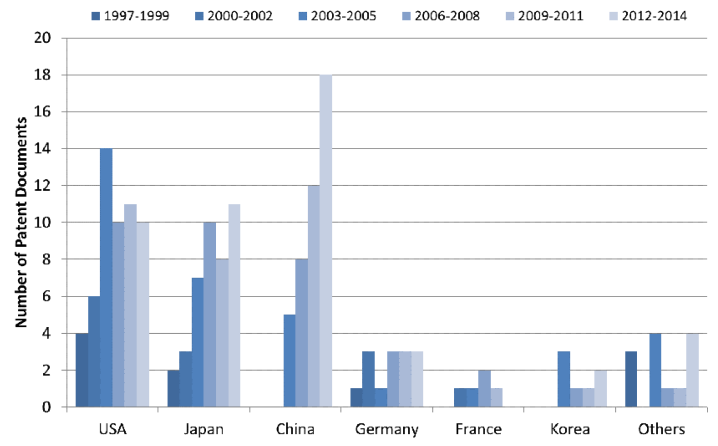

Figure 3. Number of patents regarding amorphous alloys processed by thermal spraying processes, by priority countries. Source: Derwent Innovations Index.

The percentage of patent applications related to the main technological subdomains in different timespan are presented in Figure 4. The subdomain Surface Treatment must be interpreted as consequence of the topic of this study, thus expected to be strongly present. However, the percentage value to Materials-Metallurgy subdomain trend to decrease recently while Machine-Tools, Materials Processing and Electrical Components is increasing. This may be an evidence that recent developments tend to focus on the processes rather than developing new alloys compositions.

American and Japanese companies, followed by Chinese Universities, leads the technology development for surface treatments and new amorphous alloys and represents around $70 \%$ of holders. Japanese universities also have a notable 


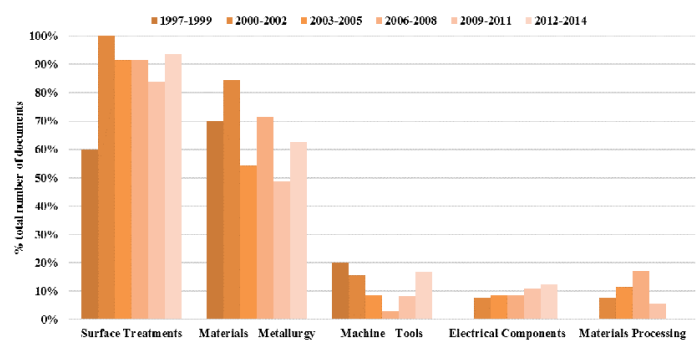

Figure 4. Main Technological Subdomains percentage representativeness of patent documents regarding amorphous alloys processed by thermal spraying between 1997 and 2014. Source: Derwent Innovations Index.

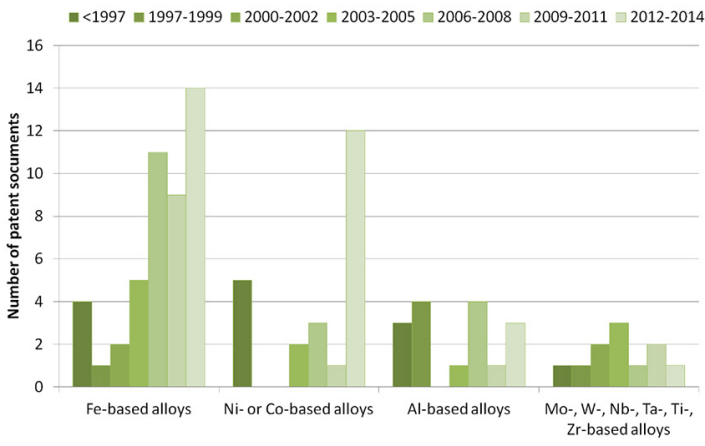

Figure 5. Number of patent documents in different periods for each main amorphous/glassy metallic alloys. Source: Derwent Innovations Index. participation in this development by its cooperation with industry which corresponds to $21 \%$ of the patents regarding the two-main technological sub-domains indicated. Despite this prominence, it is not possible to affirm that these countries will continue to lead the development of these materials, processes and applications in the coming years, since the number of patents characterizes the technology in an emerging state of development.

Different types of amorphous/glassy metallic coatings have been applied using thermal spraying process. Fe-based alloys was the most explored as coating, followed by Nior Co-based alloys, according to Figure 5. Both group of amorphous alloys presented a growth trend in terms of patent applications recently. To the other amorphous alloys, no trend could be observed as their number of patents oscillated among periods, even though a technological activity was clearly observed. Our data shows Fe-based alloys are most applied in structural and tooling applications mainly related to automobilist area due to its lower comparative costs and good wear resistance. In the case of $\mathrm{Ni}$ - or Co- based alloys, its application regards mainly electronic devices by combining good corrosion resistance and magnetic properties.

Figure 6 provides the networking between the main amorphous/glassy alloys, the detailing alloys and the types of assignee (companies and universities/research institutes).

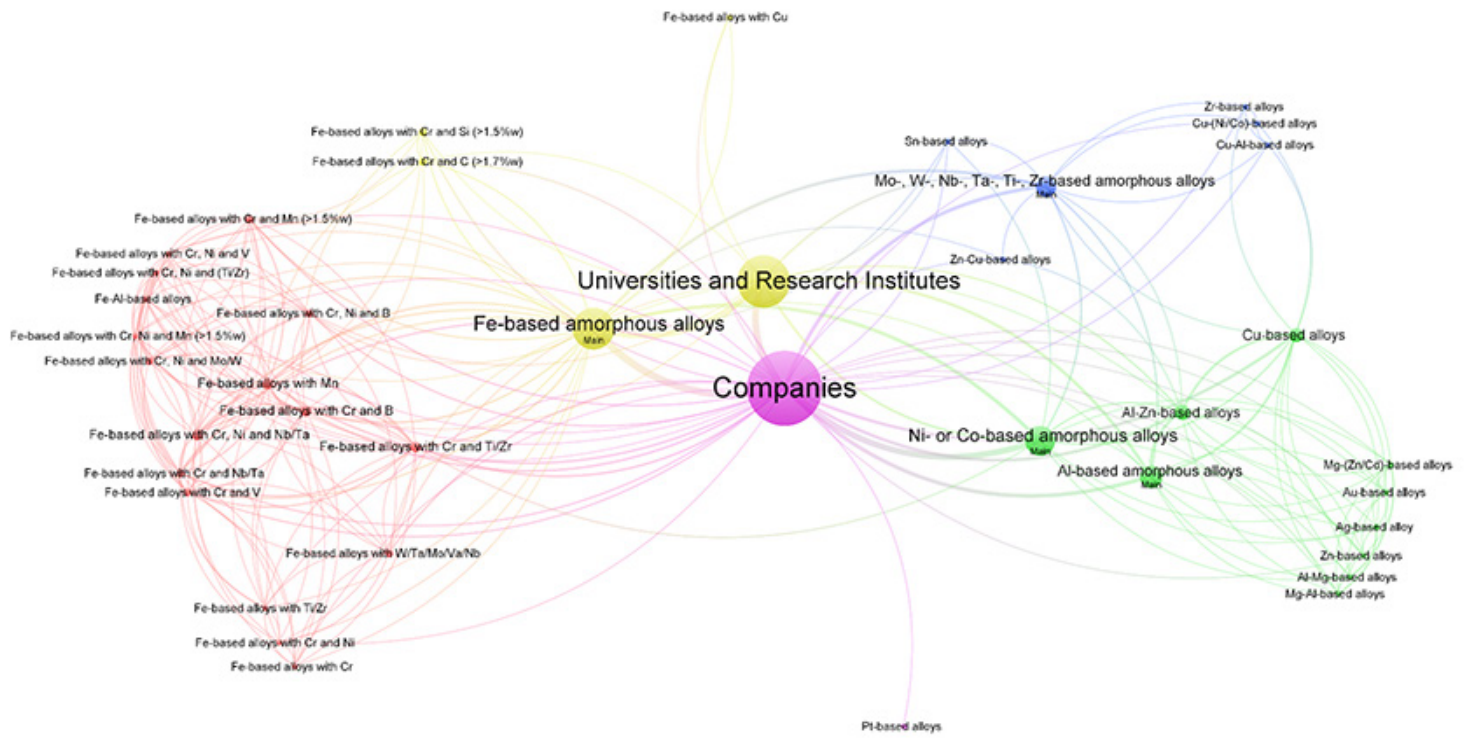

\& vosviewer

Figure 6. Companies and Universities or Research Institutes patent networking according to the main amorphous/glassy metals and their details. The nodes indicated an alloy or a type of assignee, the size of the node is proportional to the total of patent documents of it, and the lines indicates the total number of patents the nodes share; they were colored according to a cluster. 
All items were addressed to five different clusters. The amorphous/glassy alloys with a specific IPC code were marked with "main" while the other nodes provide interesting details of metallic alloys that has at least one patent document associated with.

The companies' node (pink) was centered in the map because it has connections to all other items from the net. Besides Fe-based amorphous alloys and other items from red-colored cluster, companies had much higher number associated to Ni- or Co-based amorphous alloys, Al-based amorphous alloys and Mo-, W-, Nb-, Ta-, Ti-, Zr-based amorphous alloys than the other type of assignee. Moreover, although we maintained the IPC name for this big group of alloys classification (Mo-, W-, Nb-, Ta-, Ti-, Zr-) we checked that all patents classified under this code were regarding Ti- or Zr-based alloys.

On the other hand, universities and research institutes have been more focused in their technological development. Besides the main amorphous/glassy alloys, they have patents on Al-Zn-based alloys, Fe-based alloys with $\mathrm{Cr}$ and $\mathrm{B}, \mathrm{Fe}-$ based alloys with $\mathrm{Cr}, \mathrm{Ni}$ and $\mathrm{B}, \mathrm{Fe}$-based alloys with W/ $\mathrm{Ta} / \mathrm{Mo} / \mathrm{Va} / \mathrm{Nb}$, Fe-based alloys with $\mathrm{Cr}$ and $\mathrm{Si}(>1.5 \% \mathrm{w})$, Fe-based alloys with $\mathrm{Cr}$ and $\mathrm{C}(>1.7 \% \mathrm{w}), \mathrm{Fe}$-based alloys with $\mathrm{Cu}$, and $\mathrm{Sn}$-based alloys. Furthermore, iron-based alloys with copper or with chromium and high quantities of silicon or carbon coatings are highly dependent of universities and research institutes research. Platinum alloys as an amorphous coating was a subject of companies' interest only.

\section{Conclusions}

In this study, we developed and analyzed technological indicators based mainly on metallic glass coatings applied by thermal spraying processes patent data. We focused on temporal evolution assessment and on the geographical position of patent holders, the sectors of technological interest, and on the most used metallic alloys by companies, universities and research centers.

The development of amorphous metallic coatings using thermal spraying processes is dependent of countries' innovation system and Japan, China and the USA play an important role. Moreover, the influence of Chinese research institutes and universities affected the evolutions indicators. Despite this fact, companies mainly from Japan and the USA are responsible for most of the development observed until now. The main technological subdomain of interest is related to Surface Treatments and Materials-Metallurgy, which was expected due to the topic of this study and the search expression used to retrieve patent data from Derwent Innovations Index database. However, our indicators suggest that thermal spraying process have been more focused on technological developments than new amorphous metallic alloys to be used as coatings.
Finally, we mapped that Universities and research institutes have focused mainly in Fe-based amorphous alloys while companies, besides Fe-based, also have engaged in Ni- or Co-based, Al-based, and Ti- or Zr-based amorphous alloys development. Although the procedure of analysis that considered both type of assignee and alloys provide and interesting picture of the technological development, only $36.6 \%$ from the 213 patent documents were analyzed. That indicates the need of developing new methods and procedures that could enhance the sample evaluated.

Thermal spraying processes and its application to produce amorphous/glassy alloys coatings is a technology field in an emerging state of development. We could note that this topic represents only about $1 \%$ from the total of patent filings on thermal spraying processes as a general technological area. Consequently, we recommend monitor it regularly to detect new trends that can support decision makings and R\&D management.

\section{Acknowledgements}

The authors are thankful for the funding support provided by the São Paulo Research Foundation (FAPESP) (2015/18878-8, and 2013/05987-8), Coordination for the Improvement of Higher Education Personnel (CAPES), Postgraduate Program in Materials Science and Engineering at the Federal University of São Carlos (PPG-CEM/UFSCar).

\section{References}

1. Wang WH, Dong C, Shek CH. Bulk metallic glasses. Materials Science and Engineering: R: Reports. 2004;44(2-3):45-89.

2. Inoue A. Stabilization of metallic supercooled liquid and bulk amorphous alloys. Acta Materialia. 2000;48(1):279-306.

3. Inoue A, Takeuchi A. Recent development and application products of bulk glassy alloys. Acta Materialia. 2011;59(6):2243-2267.

4. Zhou Z, Wang L, Wang FC, Zhang HF, Liu YB, Xu SH. Formation and corrosion behavior of Fe-based amorphous metallic coatings by HVOF thermal spraying. Surface and Coatings Technology. 2009;204(5):563-570.

5. Guo Y, Koga GY, Jorge AM Jr., Savoie S, Schulz R, Kiminami $\mathrm{CS}$, et al. Microstructural investigation of Fe-Cr-Nb-B amorphous/ nanocrystalline coating produced by HVOF. Materials \& Design . 2016;111:608-615.

6. Guo RQ, Zhang C, Chen Q, Yang Y, Li N, Liu L. Study of structure and corrosion resistance of Fe-based amorphous coatings prepared by HVAF and HVOF. Corrosion Science. 2011;53(7):2351-2356.

7. Liu XQ, Zheng YG, Chang XC, Hou WL, Wang JQ, Tang Z, et al. Microstructure and properties of Fe-based amorphous metallic coating produced by high velocity axial plasma spraying. Journal of Alloys and Compounds. 2009;484(1-2):300-307.

8. Nelson GM, Nychka JA, McDonald AG. Flame Spray Deposition of Titanium Alloy-Bioactive Glass Composite Coatings. Journal of Thermal Spray Technology. 2011;20(6):1339-1351. 
9. Sidhu TS, Prakash S, Agrawal RD. State of the Art of HVOF Coating Investigations-A Review. Marine Technology Society Journal. 2005;39(2):53-64.

10. Pawlowski L. The Science and Engineering of Thermal Spray Coatings. $2^{\text {nd }}$ ed. Chichester: John Wiley \& Sons; 2008. 625 p.

11. Simunovic K. Thermal spraying. Welding Engineering and Technology; 2010. Available from: <http://www.eolss.net/ sample-chapters/c05/e6-171-17-00.pdf $>$. Access in: 7/11/2017.

12. Stöver D, Pracht G, Lehmann H, Dietrich M, Döring JE, Vaßen R. New material concepts for the next generation of plasmasprayed thermal barrier coatings. Journal of Thermal Spray Technology. 2004;13(1):76-83.

13. Zhang H, Xie Y, Huang L, Huang S, Zheng X, Chen G. Effect of feedstock particle sizes on wear resistance of plasma sprayed Fe-based amorphous coatings. Surface and Coatings Technology. 2014;258:495-502

14. Kuroda S, Kawakita J, Watanabe M, Katanoda H. Warm spraying-a novel coating process based on high-velocity impact of solid particles. Science and Technology of Advanced Materials. 2008;9(3):033002.

15. Moridi A, Hassani-Gangaraj SM, Guagliano M, Dao M. Cold spray coating: review of material systems and future perspectives. Surface Engineering. 2014;30(6):369-395.

16. Martino JP. A review of selected recent advances in technological forecasting. Technological Forecasting and Social Change. 2003;70(8):719-733.

17. Martino JP. Technological Forecasting for Decision Making. New York: Elsevier Science; 1993. 404 p.

18. Watts RJ, Porter AL. Innovation forecasting. Technological Forecasting and Social Change. 1997;56(1):25-47.

19. Ashton WB, Klavans RA. Keeping Abreast of Science and Technology: Technical Intelligence for Business. $6^{\text {th }}$ ed. Columbus: Battelle Press. 1997. 560 p.

20. Organisation for Economic Cooperation and Development. Using Patent Data as Science and Technology Indicators. 1994; 108 p. Available from: $<$ https://www.oecd.org/sti/inno/2095942. pdf $>$. Access in: 7/11/2017.

21. Organisation for Economic Cooperation and Development. OECD Patent Statistics Manual. 2009. 162 p. Available from: $<$ http://www.oecd-ilibrary.org/science-and-technology/oecdpatent-statistics-manual 9789264056442-en>. Access in: 7/11/2017.

22. Milanez DH, de Faria LIL, do Amaral RM, Leiva DR, Gregolin JAR. Patents in nanotechnology: an analysis using macro-indicators and forecasting curves. Scientometrics. 2014;101(2):1097-1112.

23. Abbas A, Zhang L, Khan SU. A literature review on the state-of-the-art in patent analysis. World Patent Information. 2014;37:3-13.

24. Mogee ME. Patents and Technology Intelligence. In: Keeping Abreast of Science and Technology: Technical Intelligence for Business. Columbus: Battelle Press; 1997.
25. Daim TU, Rueda G, Martin H, Gerdsri P. Forecasting emerging technologies: Use of bibliometrics and patent analysis. Technological Forecasting and Social Change. 2006;73(8):981-1012.

26. Porter AL, Detampel MJ. Technology opportunities analysis. Technological Forecasting and Social Change. 1995;49(3):237255.

27. Okubo Y. Bibliometric Indicators and Analysis of Research Systems - Methods and Examples. OECD Science Technolpgy and Industry Working Papers No. 1997/01. Paris: OECD Publishing; 1997.

28. WIPO. International Patent Classification (IPC) Official Publication. IP Services; 2016. Available from: $<$ http://www. wipo.int/classifications/ipc/en/>. Access in: 2/5/2017.

29. Clarivate Analytics. Derwent Innovations Index; 2017. Available from: $<$ http://apps-webofknowledge.ez31.periodicos.capes.gov.br/ DIIDW_GeneralSearch_input.do?product=DIIDW\&search_mo $\mathrm{de}=$ GeneralSearch\&SID $=3 \mathrm{D} 7 \mathrm{AZDSEKnT1VrqCCjA \& prefer}$ encesSaved $=>$. Access in: 16/12/2016.

30. Milanez DH, Milanez MG, de Faria LIL, do Amaral RM, Gregolin JAR. The Earliest Priority Selector for compiling patent indicators. In: Proceedings of $14^{\text {th }}$ International Society of Scientometrics and Informetrics Conference - ISSI; $2013 \mathrm{Jul}$ 15-19; Vienna, Austria. AIT; 2013. p. 1950-1953.

31. OST. Indicateurs de Sciences et de Technologies, Édition 2010. Paris; 2010. Available from: <http://www.obs-ost.fr/sites/default/ files/R10_Complet.pdf $>$. Access in 7/11/2017.

32. OST. Observatoire des Sciences et des Techniques. Available from: <http://www.obs-ost.fr/>. Access in: 7/11/2017.

33. CWTS. VOSviewer. 2017. Available from: <http://www. vosviewer.com/>. Access in: 15/9/2017.

34. van Eck NJ, Waltman L. Text mining and visualization using VOSviewer. ISSI Newsletter. 2011;7(3):50-54

35. Oliveira BS, Ishikawa TT, de Faria LIL, Leiva DR. Monitoramento Tecnológico em ligas ferrosas utilizadas em tubos na indústria petrolífera a partir da análise de documentos de patentes. In: Proceedings of $70^{\text {th }}$ ABM Annual Conference; 2015 Aug 17-21; Rio de Janeiro, RJ, Brazil.

36. Chanchetti LF, Oviedo Diaz SM, Milanez DH, Leiva DR, de Faria LIL, Ishikawa TT. Technological forecasting of hydrogen storage materials using patent indicators. International Journal of Hydrogen Energy. 2016;41(41):18301-18310.

37. Milanez DH, Oliveira BS, Leiva DR, de Faria LIL, Botta WJ. Monitoramento tecnológico do processo de deposição a laser de ligas metálicas a partir de indicadores de patentes. In: Anais do $22^{\circ}$ CBECIMAT; 2016 Nov 6-10; Natal, RN, Brazil. p. $7433-7444$.

38. Dang J, Motohashi K. Patent statistics: A good indicator for innovation in China? Patent subsidy program impacts on patent quality. China Economic Review. 2015;35:137-155.

39. Fisch CO, Block JH, Sandner PG. Chinese university patents: quantity, quality, and the role of subsidy programs. The Journal of Technology Transfer. 2016;41(1):60-84. 